\title{
The Influence of Consumers' Interest in Healthy Eating, Definitions of Healthy Eating, and Personal Values on Perceived Dietary Quality
}

\author{
Hansen, Torben; Uth Thomsen, Thyra
}

\author{
Document Version \\ Accepted author manuscript \\ Published in: \\ Food Policy \\ DOI: \\ 10.1016/j.foodpol.2018.09.002 \\ Publication date: \\ 2018 \\ License \\ CC BY-NC-ND
}

Citation for published version (APA):

Hansen, T., \& Uth Thomsen, T. (2018). The Influence of Consumers' Interest in Healthy Eating, Definitions of Healthy Eating, and Personal Values on Perceived Dietary Quality. Food Policy, 80, 55-67.

https://doi.org/10.1016/j.foodpol.2018.09.002

Link to publication in CBS Research Portal

\section{General rights}

Copyright and moral rights for the publications made accessible in the public portal are retained by the authors and/or other copyright owners and it is a condition of accessing publications that users recognise and abide by the legal requirements associated with these rights.

\section{Take down policy}

If you believe that this document breaches copyright please contact us (research.lib@cbs.dk) providing details, and we will remove access to the work immediately and investigate your claim.

Download date: 26. Apr. 2023
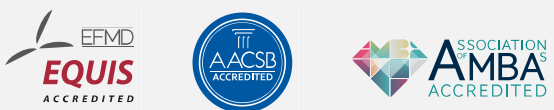


\section{The Influence of Consumers' Interest in Healthy Eating, Definitions of Healthy Eating, and Personal Values on Perceived Dietary Quality}

Torben Hansen and Thyra Uth Thomsen

Journal article (Accepted manuscript*)

\section{Please cite this article as:}

Hansen, T., \& Uth Thomsen, T. (2018). The Influence of Consumers' Interest in Healthy Eating, Definitions of Healthy Eating, and Personal Values on Perceived Dietary Quality. Food Policy, 80, 55-67.

https://doi.org/10.1016/j.foodpol.2018.09.002

\section{DOI: 10.1016/j.foodpol.2018.09.002}

* This version of the article has been accepted for publication and undergone full peer review but has not been through the copyediting, typesetting, pagination and proofreading process, which may lead to differences between this version and the publisher's final version AKA Version of Record.

Uploaded to CBS Research Portal: August 2019

(1) 2019. This manuscript version is made available under the CC-BY-NC-ND 4.0 license http://creativecommons.org/licenses/by-nc-nd/4.0/ 


\section{The influence of consumers' interest in healthy eating, definitions of healthy eating, and personal values on perceived dietary quality}

By

Torben Hansen, Professor, Ph.D.

Department of Marketing, Copenhagen Business School

Solbjerg Plads 3, 2000 Frederiksberg, Denmark Tel +4538152100 - Fax +4538152101 - E-mail th.marktg@ cbs.dk

and

Thyra Uth Thomsen, Professor mso., Ph.D.

Department of Marketing, Copenhagen Business School

Solbjerg Plads 3, 2000 Frederiksberg, Denmark Tel +4538152100 - Fax +4538152101 - E-mail tt.marktg@ cbs.dk

Acknowledgement

This research was supported by a research grant from the Danish Council for Strategic Research, Program Commission on Food and Health. 


\title{
The influence of consumers' interest in healthy eating, definitions of healthy eating, and personal values on perceived dietary quality
}

\begin{abstract}
Consumers often associate healthy food consumption with different definitions. Yet relatively little is known about how definitions of healthy eating influence perceived dietary quality. Based on an online survey of 718 Danish food consumers, the present research finds that the healthy eating definitions entitled 'healthy/unhealthy eating' and 'mind/body healthy eating' both showed positive effects on perceived dietary quality, whereas the definition 'healthy eating guideline' was not significantly related to perceived dietary quality. We also found that consumers' interest in healthy eating had a significant indirect effect on perceived dietary quality through mind/body healthy eating and that the relationships between interest in healthy eating, consumer definitions of healthy eating, and perceived dietary quality were moderated by different levels of personal values. Our results provide guidance to those seeking to influence consumers' dietary behavior based on their interest in healthy eating, definitions of healthy eating, and personal values.
\end{abstract}

Keywords: Perceived dietary quality; consumer definitions of healthy eating; interest in healthy eating; personal values 


\section{Introduction}

Food policy makers are facing an obesity crisis. At least $51 \%$ of European adults (Eurostat, 2018) and $68 \%$ of U.S. adults are overweight with BMIs of 25+ (Caroll et al., 2016). Overweight individuals face increased rates of certain diseases, which include respiratory problems, cardiovascular-related diseases, diabetes, and some types of cancer, among others (Mokdad et al., 2003; Buckmueller and Johar, 2015; Taubes, 2012; Jeong and Ham, 2018; WHO, 2017). Food consumption is known as a central means to the reduction of weight and pursuit of health (McCarthy et al., 2013) and food policy makers and government authorities have in many years stressed the importance of the food choice - health link (e.g., Luomala et al., 2006; McCarthy et al., 2013; WHO, 2017). To that end, prior consumer and food research has in particular investigated how healthy eating is related to consumers' mental and emotional states as well as demographic, psychographic, behavioral, environmental, and situational factors (e.g., Halkier 2016; Hill et al., 2018; French et al., 2012; Chandon and Wansink, 2007; Howlett et al., 2008; Hughner and Maher, 2006; Khare and Inman, 2006; Kidwell et al., 2008). However, the question of why people may or may not carry out healthy eating is still not fully understood (Orquin and Scholderer, 2015; Shukri et al., 2018; Hill et al., 2018). Moreover, there is an increased understanding that 'healthy eating' is a multifaceted concept, which not only relates to nutritional guidelines but also relates to the various definitions that consumers may associate with healthy food consumption (Luomala et al., 2006; Forstmann et al., 2012; Delormier et al., 2009).

Research suggests that people may differ in their personal values, their interest in healthy eating, and that they may construct different definitions of 'healthy eating' (Hansen et al., 2018; Luomala et al., 2006; Delormier et al., 2009; Van Loo et al., 2017). However, even though the literature recommends an increased focus on the links between values, definitions of healthy eating, interest in healthy eating, and dietary quality (e.g., de Maya et al., 2011; Luomala et al., 2006; 
Forstmann et al., 2012; Kristensen et al., 2013), the relationships among such constructs remain poorly understood. For example, to what extent do definitions of healthy eating influence perceived dietary quality? How does the interplay between consumers' values and definitions of healthy eating influence perceived dietary quality? Also, how does consumers' interest in healthy eating influence their definitions of healthy eating?

The purpose of this study is twofold. First, we develop and present a conceptual model, which specifies (a) direct relationships between consumer interest in healthy eating, definitions of healthy eating, and perceived dietary quality and (b) moderating influences of personal values on these relationships. In this study, we define perceived dietary quality as the extent to which the consumer on average believes s/he has a healthy food intake (Moorman and Matulich, 1993) and consumer interest in healthy eating as the degree of personal importance and relevance a consumer attaches to healthy eating (Beatty et al., 1988; Zaichowsky, 1985). Consumer definitions of healthy eating are conceptualized as individuals' ideas of what constitutes healthy food consumption (Luomala et al., 2006; Swanson et al., 2013).

Second, we empirically estimate the model using a survey sample of 718 food consumers. The results of this study may be highly important for policymakers, food authorities, food managers, and others seeking solutions to healthy eating problems that require behavioral change.

\section{Conceptual framework}

We suggest that consumers' definitions of healthy eating mediate the link between interest in healthy eating and perceived dietary quality. While interest in healthy eating may well be an antecedent to perceived dietary quality, previous research suggests that motivational constructs are more likely to influence behavior through intervening variables (e.g., de Pelsmacker et al. 2016; Hansen et al. 2018). This view is also consistent with established consumer paradigms suggesting 
that consumer mental constructions can be seen as intervening variables between their motivations and behavior (e.g., Ajzen and Fishbein, 1973; Warshaw, 1980; Arnocky et al., 2007). We build upon this perspective in the proposed conceptual model (Figure 1).

\section{Fig. 1.}

Conceptual model

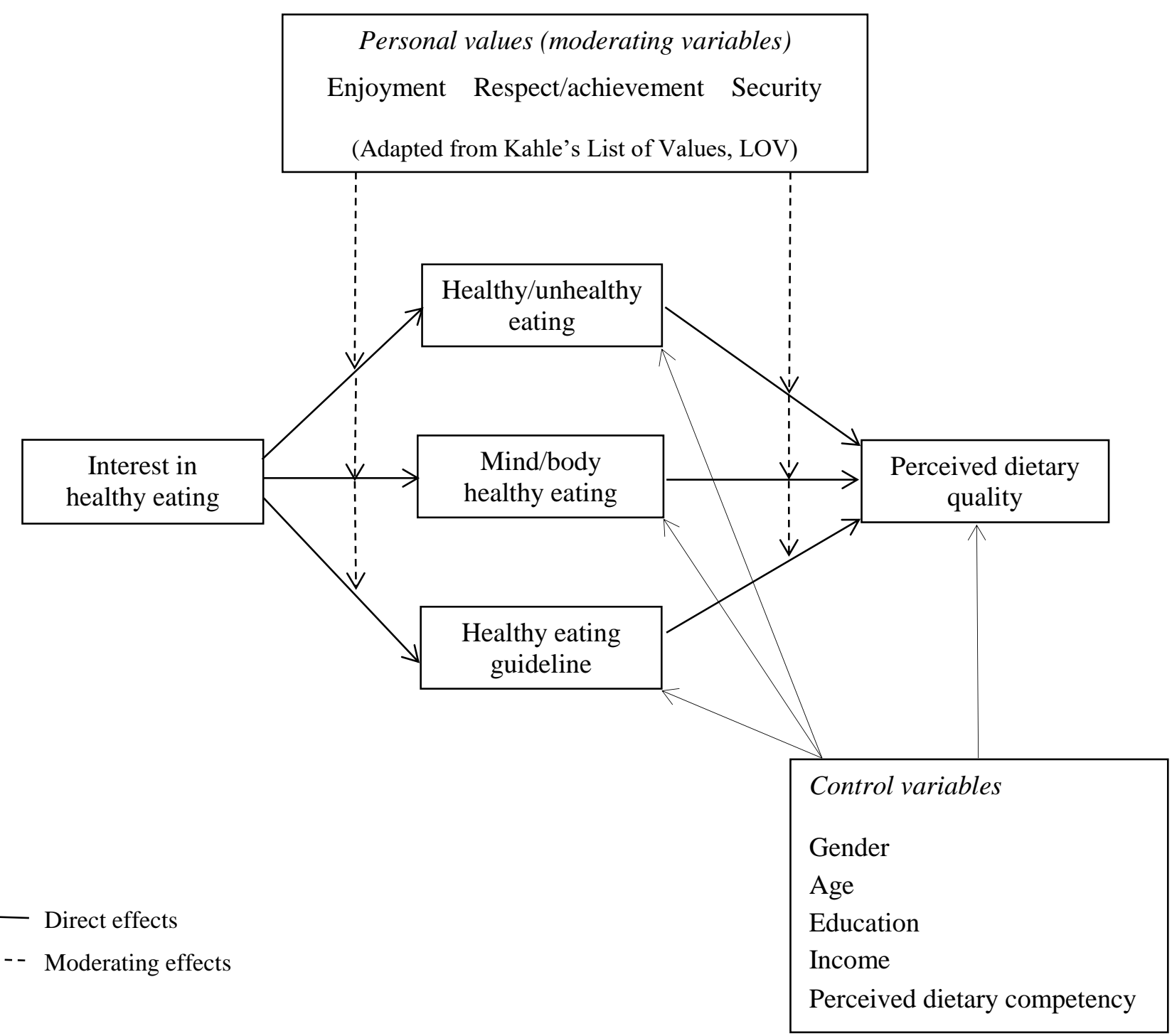




\subsection{Direct effects}

When asked to report the healthiness of their diet individuals may be inclined to underestimate unhealthy behaviors (Fisher, 1993; McLaughlin et al., 2018). This measurement bias has been found to be especially prevalent among overweight individuals (McLaughlin et al., 2018). Previous research has used different methods in measuring individuals' (self-reported) dietary behavior, including perceived dietary behavior (Loo et al., 2017; Hill et al., 2018; Slater, 2016), reported frequency of consumption of various food items such as fruits, vegetables, sweets and snacks, among others (Hilger et al., 2017; Metcalfe and Fiese, 2018; Swan et al., 2016), and statements given in qualitative interviews (Swanson et al., 2013). Other studies have relied on observed behavior, such as experiments (Rizk and Treat, 2014) and scanner data (e.g., Jones et al., 2003), in investigating dietary quality.

This study focuses on consumers' perceived dietary quality. First, prior research indicates that individuals' self-perception of overall dietary quality is reflective of their (self-reported) actual dietary behavior. In a study of 1,000 adults Sharif et al. (2016) found that self-perceived healthy eating habits were positively associated with higher consumption of fruit and vegetables and negatively associated with drinking soda and eating fast food. In a large-scale study of 15,283 adolescents, Velazquez et al (2011) found that self-perceptions of dietary practices were significantly associated with dietary behaviors. Supporting these results, Davenport et al. (2014) found that adolescents who perceive their diet as healthy consume more fruits, vegetables and milk and fewer sweet drinks. Second, while our measurement of dietary quality may still be biased in assessing the healthiness of individuals' dieting behavior, we cross-validated the outcome of the applied measure against the suggestion that an unhealthy diet is positively linked to overweight (e.g., WHO, 2017), see section 4.1 below. 
While consumers may define healthy eating in various ways, a literature review suggests that three healthy eating definitions, in particular, may be dominant among food consumers: Healthy/unhealthy eating, mind/body healthy eating, and healthy eating guideline.

Food consumers may construct healthy food consumption as a balance between healthy and unhealthy food items (Luomala et al., 2006; Thompson and Troester, 2002). This definition reflects the idea that unhealthy food intake may be balanced out by healthy food intake. For instance, consumers may believe that products relatively high in fat may be balanced out by an extra intake of fruit or vegetables. This is also witnessed by the 'licensing effect', which suggests that consumers are more inclined to buy vice (e.g., unhealthy) products after having added virtue (e.g., healthy) products to their shopping carts (Hui et al., 2009). By focusing on both healthy and unhealthy food items this definition of healthy eating contrasts a more nutritionist discourse, which stresses the functionalist and nutritional aspects of food (Fischler, 1990; Pollan, 2008).

The mind/body healthy eating definition constructs food related health as a balance between physical and mental health. Consumers adhering to this definition of healthy eating tend to believe that body and mind are inextricably connected (Forstmann et al., 2012) and that healthy eating must include emotional well-being (Geeroms et al., 2008a, 2008b). Thereby, this definition of healthy eating contrasts the classic body concept: the Cartesian mind-body dualism (Casotti, 2004; Ecks, 2009), which sees mind and body as two distinct entities (Forstmann et al., 2012).

Health Authorities promote a more 'official' definition of food related health, which we term 'healthy eating guideline'. Consumers adhering to this definition may believe that they risk being unhealthy if they fail to comply with official healthy eating guidelines. Also, they tend to express the relationship between health and food in scientific and nutrition informed terms (Coveney, 2004; Delormier et al., 2009). This definition is reflected in research distinguishing 
between impulsive food behavior and behavior that is more controlled and planned upon guidelines (French et al., 2012; Reynolds et al., 2006).

Our model includes the expectation that consumers' interest in healthy eating may influence how they define healthy eating. Our expectations are consistent with past research suggesting that interests in a specific area may lead a person to attach meanings related to that area (Tarkiainen and Sundqvist, 2009). If consumers find healthy food consumption to be of high relevance and importance, they should be more likely to make a significant effort to develop definitions of healthy eating (Olsen 2003; Franke et al., 2009; Loo et al., 2017).

Consumers with relatively high levels of interest in healthy eating may be more likely to show relationships between interest in healthy eating and more 'demanding' healthy eating definitions, such as healthy eating guideline, which in turn may positively influence the healthiness of their dietary behavior. This is because these consumers may perceive a higher risk if they fail to comply with official guidelines and may also be more likely to seek correspondence between their interest in healthy eating and their dietary behavior. Notably, highly motivated individuals tend in particular to avoid disconfirming behavior in order to maintain feelings of consistencies between their beliefs (i.e., their healthy eating definitions) and their actions (Todd and Gigerenzer, 2003). In contrast, individuals with lower levels of interest may tend to be more inclined to ignore disconfirming behavior and definitions, because they have more compelling justification for acting in 'inconsistent' manners - the lower perceived importance and relevance (Todd and Gigerenzer, 2003; Osgood and Tannenbaum, 1955).

Also, individuals adhering to the healthy eating guideline may be less impulsive in their dietary behavior. Impulsive consumers may prefer energy dense foods now, rather than the delayed consequence of weight control and unhealthy eating later (French et al., 2012), which in turn may negatively affect the healthiness of their dietary behavior. In contrast, individuals adhering to 
healthy/unhealthy eating may be less inclined to postpone unhealthy food intakes since these can be compensated by eating more healthy food on other occasions. Also, people who perceive their minds and bodies to be distinct entities may engage less in behaviors that protect their bodies (Forstmann et al., 2012). In summary, we seek to answer the following research questions:

RQ1: In what way do healthy eating definitions influence consumers' perceived dietary quality?

RQ2: In what way do interest in healthy eating influence consumers' definitions of healthy eating?

RQ3. In what way do definitions of healthy eating mediate the relationships between interest in healthy eating and perceived dietary quality?

\subsection{Moderating effects}

Consumer values can be regarded as central to consumer decision making (e.g., Grebitus et al., 2015). Past research on the relationship between values and food choice (Halkier 2016; Finch, 2005; Dibley and Baker, 2001; Homer and Kahle, 1988; Kropp, Lavack, and Holden, 1999) suggests that values have a positive impact on food product choice if the product is congruent with a value that is central to the consumer. Consumer values can be understood as trans-situational goals that serve the interest of individuals or groups and act as principles that guide people in their lives and in their behavioral considerations (Schwartz and Sagiv, 1995).

Several value theories have been applied in consumer research, including Rokeach's value system (RVS) (Rokeach, 1973; Johnston, 1995), Schwartz' theory about values (Schwartz, 1994; Schwartz and Sagiv, 1995), and Kahle's List of Values (LOV) (Kahle and Kennedy, 1989; Kahle et al., 1992). Since RVS is concerned with values far from everyday life, such as national security, 
world peace and the like, this measurement system was not considered appropriate for this study. Schwartz' value system is more directed at the individual but does not put high focus on certain values, such as enjoyment, which previous research has related to dietary quality (e.g., French et al., 2012). Instead, we found LOV to be the most suitable for the present research since it offers a representation of values (including enjoyment) that are often linked to dietary behavior. Moreover, Kahle (1983) specifically developed LOV in order to measure the influence of cultural values on consumer behavior. LOV consists of nine values that are believed to relate to the general motivations that people have in their everyday life (Kahle, 1983; McCarty and Shruni 1993). The nine values may, in turn, be grouped into three overall dimensions: Enjoyment (excitement, fun \& enjoyment), respect/achievement (sense of accomplishment, self-respect, self-fulfillment, and being well-respected), and security (sense of belonging, warm relationships, and security) (Kahle, 1983; McCarty and Shruni, 1993).

We expect that the difference in importance that individuals attach to these personal values may lead to differences in the relative importance of each of the paths in the conceptual framework displayed in Figure 1. For example, consumers adhering more to enjoyment values may be more likely to show positive relationships between interest in healthy eating, healthy/unhealthy eating, and perceived dietary quality. On the other hand, consumers adhering more to security values may be more likely to show positive relationships between interest in healthy eating, healthy eating guideline, and perceived dietary quality. Also, consumers adhering more to respect/achievement values may feel more inclined to express their preferred healthy eating definition directly into their food behavior, whereas consumers adhering more to enjoyment values may exhibit lower tendency to seek correspondence between their preferred healthy eating definition and their dietary behavior even if motivated. In summary, we seek to answer the following research questions: 
RQ4. In what way do personal values moderate the relationships between interest in healthy eating, definitions of healthy eating, and perceived dietary quality? RQ5. To what extent do personal values determine the mediating role of definitions of healthy eating in the relationship between interest in healthy eating and perceived dietary quality?

\subsection{Control variables}

A number of control variables that may be related to the endogenous constructs (constructs that act as dependent variables in at least one of the model relationships, i.e., healthy/unhealthy eating, mind/body healthy eating, healthy eating guideline, and perceived dietary quality) in the conceptual model are taken into account (e.g., Greene, 2000). Based on previous research, we included gender, age, educational level, income, and perceived dietary competency level as control variables in the analysis. Several studies have indicated that age (Bartali et al. 2003), educational level (Monteiro et al., 2001), perceived dietary competency (Ronto et al., 2016; Fitzgerald et al., 2008; Zinkhan and Braunsberger, 2004), and income (Wang et al., 2002) are all related to healthy dietary behavior. Also, past research suggests that women are more likely than men to show a healthy dietary behavior (French et al. 1999; Ureña et al., 2008).

\section{Methodology}

\subsection{Measurements}

Nine of the variables in Figure 1 (i.e., interest in healthy eating, the three health definitions, perceived dietary quality, the three personal values, and perceived dietary competency) were all measured by multiple items. The measurement items for the three personal values ranged from (1=not at all important) to $7(=$ extremely important), whereas the measurement items for the 
remaining six variables ranged from 1(=strongly disagree) to 7(=strongly agree). The items for each variable are summarized in Appendix B. Gender (with codings: $0=$ male; $1=$ female), age, educational level, and income were all measured by a single item (see Table 1).

In measuring 'interest in healthy eating', we draw on Beatty and Talpade (1994) and Beatty et al. (1988). Perceived dietary quality was assessed as the extent to which the consumer on average believes s/he has a healthy food intake. This measure is similar to measures used in past studies on food choice decision making (Moorman and Matulich, 1993). We cross-validated this measure by asking respondents to state their weight and height, which allows for a calculation of their body mass index $(\mathrm{BMI})$; BMI=weight $(\mathrm{kg}) /$ height $^{2}\left(\mathrm{~m}^{2}\right)(\mathrm{WHO}, 2017) .51 .4 \%$ of the respondents reported a BMI of 25+, which corresponds to the percentage (51.0) in the Danish population (The Danish Health Authority, 2017). 39.8\% of the respondents reported overweight (BMI 25-<30) (34.2\% in the population) and $11.7 \%$ reported obesity (16.8\% in the population). Appendix A further details the distribution of BMI across gender and age. The official belief is that an unhealthy diet is positively linked to overweight (WHO, 2017) and thus a negative correlation between perceived dietary quality and BMI should be expected. The correlation between these two variables was significant in the expected direction $(\mathrm{r}=-0.12, p<0.01)$ indicating that our perceived dietary quality measure is reasonably valid; bearing in mind that also other factors, such as physical activity and genetic aspects, are known to influence BMI (Eek and Östergren, 2007; WHO, 2017).

Kahles (e.g., Kahle, 1983; Kahle et al., 1992) List of Values (LOV) scale measured the three personal values (i.e., enjoyment, respect/achievement, and security) applied in this study. To generate measures for the three food health balances, the existing literature (e.g., Luomala et al., 2006, 2015; Thompson and Troester, 2002; Fischler, 1990; Pollan, 2008; Forstmann et al., 2012; Geeroms et al., 2008a, 2008b; Casotti, 2004; Ecks, 2009; Coveney, 2004; Delormier et al., 2009; French et al., 2012; Reynolds et al., 2006; Kristensen et al., 2013) served as our starting point. Next, 
16 depth interviews (with an even distribution of men and women) were conducted with eight interviewees with varied income and educational backgrounds and with eight master students majoring in marketing and economics. The purpose was to generate items that could be associated with healthy eating definitions with special attention to the three prominent definitions identified in previous research. During this process items were evaluated for the closest match to and suitability for our study's objectives and context. The resulting items are reported in Appendix B. Perceived dietary competency was measured by three items derived from Beatty and Talpade (1994) and Berg (2007).

\subsection{Data collection}

The data collection was carried out by the market research agency Gallup using its online consumer panel consisting of approx. 30,000 Danish consumers. 1460 respondents were drawn to be representative of consumers aged 18+ and were screened such that only consumers who regularly carry out food shopping were included. 762 questionnaires were received from the respondents, corresponding to $52.1 \%$ of the 1460 mailed out. After elimination of questionnaires due to incomplete responses, the final sample consisted of 718 respondents (Table 1). The 762 participating respondents all received a monetary payout and also participated in a lottery in which they could win an additional monetary payout. In addition to the four demographic variables (Table 1), the survey contained 29 questions (Appendix B).

Of the final sample respondents, $54.1 \%$ were women, the average household size was 2.5 , and the average age was 52.0 years and ranged between $18-88$ years with a fairly normal spread. We investigated whether our sample deviates from the Danish population (aged 18-88) on gender, educational level and income level. The conducted $\chi^{2}$-tests produced all p-values $>0.05$, suggesting that our sample reflects the Danish population on the investigated criteria. 


\section{Table 1}

Socioeconomic characteristics of the sample compared to the Danish population

\begin{tabular}{|c|c|c|c|}
\hline Variable & Specification & $\begin{array}{l}\text { Percentage of the } \\
\text { sample }(n=718)\end{array}$ & Danish population (2016) \\
\hline \multirow[t]{2}{*}{ Gender } & Female & 54.1 & 50.4 \\
\hline & Male & 45.9 & 49.6 \\
\hline \multirow[t]{7}{*}{ Age (years) } & $18-24$ & 6.5 & 11.0 \\
\hline & $25-34$ & 10.6 & 14.8 \\
\hline & $35-44$ & 17.5 & 16.2 \\
\hline & $45-54$ & 17.7 & 17.9 \\
\hline & $55-64$ & 21.6 & 16.1 \\
\hline & $65-74$ & 20.2 & 14.9 \\
\hline & $75-88$ & 6.1 & 8.9 \\
\hline \multirow[t]{5}{*}{ Income $(\mathrm{DKK})^{\mathrm{b}}$} & $<200.000$ & 34.4 & 32.0 \\
\hline & 200.000-399.999 & 47.2 & 45.1 \\
\hline & 400.000-699.999 & 15.4 & 19.4 \\
\hline & 700.000-999.000 & 1.8 & 1.9 \\
\hline & $>1.000 .000$ & 0.6 & 1.6 \\
\hline \multirow[t]{6}{*}{ Education $^{c}$} & Without any graduation & 0.0 & 0.4 \\
\hline & Primary school & 32.0 & 25.2 \\
\hline & High school & 6.9 & 8.7 \\
\hline & Business training & 34.7 & 35.4 \\
\hline & Short advanced study & 4.6 & 4.4 \\
\hline & $\begin{array}{l}\text { Medium/long } \\
\text { advanced study }\end{array}$ & 22.0 & 25.9 \\
\hline
\end{tabular}

\section{Notes}

${ }^{\text {a }}$ Frequencies pertain to the Danish population aged 18-88.

b100 DKK (Danish Kroner) $\approx 16$ USD.

c Population percentages are from 2015. 'Business training' includes educations such as carpenter, glazier, and electrician; 'short advanced study' includes undergraduate degrees such as teacher, accountant, and registered nurse; 'medium/long advanced study' includes graduate degrees, i.e., bachelor's, master's, and Ph.D. degrees. Source (population percentages): Danish Statistical Bureau, DST (2018). 


\section{Results}

\subsection{Specification of the investigated model}

Previous research has used a number of techniques for estimating relationships between dietary quality and a set of explanatory variables, including multiple regression analysis (e.g., Metcalfe and Fiese, 2018), logistic regression (e.g., Swan et al., 2015), and structural equation modelling (e.g., Beydoun and Wang, 2008; Sapp and Jensen, 1998), among others. For several reasons, we chose a structural equation model (SEM) approach over more traditional regression analyses: First, SEM allows for a simultaneous examination of all the proposed relationships in the conceptual model (Figure 1) rather than separate regression analyses. Second, SEM takes into account measurement error and control variables while at the same time handling a large number of relationships between variables. Third, while regression analysis is suitable for incorporating moderating (i.e., interaction) effects, SEM is recommended for evaluation of a conceptual model that also includes mediating variables (Hair et al., 2014). Based on such considerations, the conceptual model was translated into a structural equation model (SEM) consisting of a measurement part (confirmatory factor analysis, CFA) and a structural equation part (simultaneous linear regression). We used SPSS Amos 24 to calculate the results using a maximum-likelihood estimation procedure.

\subsection{Validation of the measurement model}

The measurement model yields a chi-square $\left(\chi^{2}\right)$ of 1160.91 (d.f. $=314, p<0.01$ ). However, the Hoelter(0.05) (Hoelter, 1983) estimate ( $\mathrm{n}=221)$ suggests that the lack of absolute fit can be explained by sample size. Thus, since the chi-square test is highly sensitive to sample size other fit measures are given greater prominence in evaluating model fit (e.g., Ye et al., 2007). The root mean square error of approximation (RMSEA=0.061), the comparative fit index $(\mathrm{CFI}=0.91)$ and the normed fit index $(\mathrm{NFI}=0.89)$ suggest that the measurement model fits the data reasonably well 
(Bagozzi and Yi, 1988; Browne and Cudeck, 1993). Composite reliabilities all exceeded 0.70

indicating a good reliability of each of the measured constructs.

\section{Table 2}

Confirmatory factor analysis results

\begin{tabular}{|c|c|c|c|c|}
\hline Construct/indicator & $\begin{array}{l}\text { Stand. } \\
\text { factor } \\
\text { loading }\end{array}$ & $\begin{array}{l}\text { Critical } \\
\text { ratio }\end{array}$ & $\begin{array}{l}\text { Composite } \\
\text { reliability }\end{array}$ & $\begin{array}{r}\text { Extracted } \\
\text { variance }\end{array}$ \\
\hline Healthy/unhealthy eating & & & 0.73 & 0.47 \\
\hline X1 A good balance between healthy and unhealthy food & 0.52 & - & & \\
\hline X2 That I eat both healthy and unhealthy food & 0.69 & 11.04 & & \\
\hline X3 That an unhealthy diet is supplemented with healthy food & 0.75 & 11.12 & & \\
\hline Mind/body healthy eating & & & 0.85 & 0.60 \\
\hline X4 Feeling good about what I eat & 0.62 & - & & \\
\hline X5 That my body and soul are in balance & 0.82 & 16.96 & & \\
\hline X6 That both my body and soul are well & 0.83 & 17.01 & & \\
\hline X7 That my diet takes both my body and soul into account & 0.80 & 16.72 & & \\
\hline Health eating guideline & & & 0.87 & 0.63 \\
\hline X8 Following the official dietary guidelines & 0.86 & - & & \\
\hline X9 Eating '6-a-day’ & 0.73 & 21.81 & & \\
\hline X10 Consuming food in accordance with the food pyramid & 0.79 & 24.05 & & \\
\hline X11 Food consumption in accordance with the & 0.78 & 23.61 & & \\
\hline National Board of Health's recommendations & & & & \\
\hline Food health involvement & & & 0.80 & 0.57 \\
\hline X12 I'm usually bored when I listen to discussions about food and health* & 0.63 & - & & \\
\hline $\mathrm{X} 13$ Eating healthy is not important to me* & 0.86 & 18.14 & & \\
\hline X14 In general, I'm very interested in healthy food products & 0.76 & 16.77 & & \\
\hline Food health behavior & & & 0.81 & 0.60 \\
\hline $\mathrm{X} 15$ On average, I believe that my food intake is healthy & 0.62 & - & & \\
\hline X16 On average, I believe that my intake of drinks is healthy & 0.90 & 17.66 & & \\
\hline X17 All in all, I don't believe that I have a healthy diet* & 0.77 & 16.44 & & \\
\hline Enjoyment & & & 0.73 & 0.57 \\
\hline X18 Excitement & 0.75 & - & & \\
\hline X19 Fun \& enjoyment & 0.76 & 18.35 & & \\
\hline Respect/achievement & & & 0.78 & 0.47 \\
\hline X20 Sense of accomplishment & 0.71 & - & & \\
\hline X21 Self-respect & 0.61 & 15.20 & & \\
\hline X22 Self-fulfillment & 0.69 & 17.20 & & \\
\hline X23 Being well-respected & 0.73 & 17.99 & & \\
\hline Security & & & 0.76 & 0.51 \\
\hline X24 Sense of belonging & 0.73 & - & & \\
\hline X25 Warm relationships & 0.72 & 17.22 & & \\
\hline X26 Security & 0.69 & 16.65 & & \\
\hline Food health competency & & & 0.72 & 0.57 \\
\hline $\begin{array}{l}\text { X27 As far as shopping for healthy food is concerned, I consider myself } \\
\text { highly competent }\end{array}$ & 0.91 & - & & \\
\hline X28 I find it difficult to put together a healthy meal* & 0.56 & 14.39 & & \\
\hline
\end{tabular}

\footnotetext{
${ }^{\text {a }}$ One item for each construct was set to $1 . *$ Item reverse coded.
} 
Convergent validity of individual constructs in the model is confirmed to an acceptable degree because the mean of the squared factor loadings was greater than 0.50 for all constructs except for healthy/unhealthy eating and respect/achievement, which however in both cases showed a marginally acceptable value of 0.47 (Table 2).

In order to investigate discriminant validity, the method proposed by Fornell and Larcker (1981) was initially applied. According to this method, the extracted variance for each individual construct should be greater than the squared correlation (i.e., shared variance) between constructs. An examination of Table 3 shows that the extracted variance for each of the constructs exceeds the squared correlation except for 'interest in healthy eating' with respect to its correlation with 'perceived dietary competency' (variance, interest in healthy eating $=0.57$ <squared correlation, interest in healthy eating-perceived dietary competency=0.79), although the latter is below the suggested threshold of 0.85 (Frambach et al., 2003). Also, as the control variable 'perceived dietary competency' was included in the study because of its anticipated high correlations with endogenous model constructs, the relatively high correlation should not be regarded as a serious violation of discriminant validity. 


\section{Table 3}

Discriminant validity and descriptive statistics

\begin{tabular}{|c|c|c|c|c|c|c|c|c|c|}
\hline Construct & 1 & 2 & 3 & 4 & 5 & 6 & 7 & 8 & 9 \\
\hline 1. Healthy/unhealthy eating a, c & 0.47 & & & & & & & & \\
\hline 2. Mind/body healthy eating ${ }^{a, c}$ & 0.26 & 0.60 & & & & & & & \\
\hline 3. Healthy eating guideline $\mathrm{e}^{\mathrm{a}, \mathrm{c}}$ & 0.13 & 0.22 & 0.63 & & & & & & \\
\hline 4. Interest in healthy eating a & 0.04 & 0.30 & 0.37 & 0.57 & & & & & \\
\hline 5. Perceived dietary quality ${ }^{a}$ & 0.02 & 0.21 & 0.16 & 0.48 & 0.60 & & & & \\
\hline 6. Enjoyment ${ }^{\mathrm{b}}$ & 0.05 & 0.22 & 0.07 & 0.15 & 0.12 & 0.57 & & & \\
\hline 7. Respect/achievement ${ }^{\mathrm{b}}$ & 0.10 & 0.36 & 0.14 & 0.17 & 0.14 & 0.46 & 0.47 & & \\
\hline 8. Security ${ }^{\mathrm{b}}$ & 0.16 & 0.32 & 0.21 & 0.19 & 0.03 & 0.47 & 0.46 & 0.51 & \\
\hline 9. Perceived dietary competency ${ }^{a}$ & 0.02 & 0.18 & 0.22 & 0.79 & 0.56 & 0.12 & 0.13 & 0.12 & 0.57 \\
\hline Mean & 4.28 & 5.20 & 4.44 & 5.18 & 4.94 & 5.58 & 5.57 & 5.68 & 5.13 \\
\hline Std. deviation & 1.34 & 1.24 & 1.37 & 1.35 & 1.34 & 1.08 & 0.91 & 1.04 & 1.29 \\
\hline
\end{tabular}

Notes

Diagonals represent average amount of extracted variance for each construct. Non-diagonals represent the shared variance between constructs (calculated as the squares of correlations between constructs).

All correlations among constructs were significant on the 0.01 level.

${ }^{a}$ Averaged scale means are reported; items were measured on 7-point Likert scales $(1=$ strongly disagree; $7=$ strongly agree).

${ }^{\mathrm{b}}$ Averaged scale means are reported; items were measured on 7-point scales 1 (=not at all important; 7=extremely important).

'Percentages of respondents adhering strongly (mean=6, or higher) to each of the three healthy eating definitions, respectively: 13.2(healthy/unhealthy eating), 32.2(mind/body healthy eating), and 17.0(healthy eating guideline). Percentage of respondents adhering strongly to both healthy/unhealthy eating and mind/body healthy eating: 10.2; percentage adhering strongly to both healthy/unhealthy eating and healthy eating guideline: 5.8 ; percentage adhering strongly to both mind/body healthy eating and healthy eating guideline: 12.5 ; percentage adhering strongly to all three definitions: 5.4 .

Mind/body healthy eating was the predominating consumer definition of healthy eating (mean=5.20) (Table 3). The mean for mind/body healthy eating was significantly higher than the means for healthy/unhealthy eating $($ mean $=4.28)(t=17.67, p<0.01)$ and healthy eating guideline $($ mean $=4.44)(t=14.53, p<0.01)$, respectively. The results also suggested that respondents adhered more to healthy eating guideline than to healthy/unhealthy eating $(t=2.44, p=0.02)$. The percentages of respondents adhering strongly (mean=6, or higher) to each of the three definitions were 
13.2(healthy/unhealthy eating), 32.2(mind/body healthy eating), and 17.0(healthy eating guideline), respectively. Appendix B displays the percentages of respondents who chose 1 or 2 and 3, 4 or 5 and 6 or 7, respectively, on each of the measurement items applied in this study

In order to assess the effects of common-method variance, we re-estimated the measurement model by adding a same-source factor (all main construct items loading on it) to the CFA model (Netemeyer et al., 1997). Common method variance refers to the amount of spurious covariance shared among variables because of the common method used in collecting data (Buckley et al., 1990) and is a known limitation in surveys using self-reported measures. Comparing an unconstrained model, in which all indicators are related to a common factor, to one in which these paths are constrained to zero represents a significance test of the effects of the same-source factor. The fit of the constrained model was $\chi^{2}=918.75$ (d.f. $=313$ ); CFI $=0.93$; RMSEA $=0.056$. For the unconstrained model, the fit was $\chi^{2}=883.55$ (d.f. $=286$ ); $\mathrm{CFI}=0.94 ; \mathrm{RMSEA}=0.054$. The fit of the unconstrained model did not differ from that of the constrained model $\left(\Delta \chi^{2}=35.20, \Delta\right.$ d.f. $=27$, $p=0.13$ ) suggesting that the results are robust with respect to common method variance.

\subsection{Results pertaining to $R Q$ 's $1-3$}

The direct effects model fits the data reasonably well $\left(\chi^{2}=828.00\right.$ (d.f. $\left.=193, p<0.01\right)$; CFI $=0.91$; $\mathrm{NFI}=0.89 ; \mathrm{RMSEA}=0.068$; Hoelter(0.05)=197). Interest in healthy eating was positively related to healthy/unhealthy eating $(\beta=0.52, p<0.01), \mathrm{CI}(95 \%)=[0.33,0.64]), \mathrm{mind} /$ body healthy eating $(\beta=0.69, p<0.01), \mathrm{CI}(95 \%)=[0.53,0.78])$, and healthy eating guideline $(\beta=0.71, p<0.01)$, $\mathrm{CI}(95 \%)=[0.63,0.78])$, respectively (Table 4). In order to test the difference between coefficients, their corresponding $95 \%$ confidence intervals (CI) were estimated using bias-corrected bootstrap. If the confidence intervals overlap with less than $50 \%$, the coefficients can be considered significantly different from each other $(p<0.05)$ (Cumming, 2009). This criterion suggests that the effects of 
interest in healthy eating on mind/body healthy eating and healthy eating guideline, respectively, are both significantly larger than the effect of interest in healthy eating on healthy/unhealthy eating.

Healthy/unhealthy eating $(\beta=0.29, p<0.01), \mathrm{CI}(95 \%)=[-0.05,0.78])$ and $\operatorname{mind} /$ body healthy eating $(\beta=0.33, p<0.01), \mathrm{CI}(95 \%)=[0.15,0.52])$ were, in turn, both positively related to perceived dietary quality, whereas healthy eating guideline showed no influence on perceived dietary quality $(\beta=0.09, p=0.12), \mathrm{CI}(95 \%)=[-0.08,0.32])$. The Cumming's (2009) criterion also suggests that the effects of healthy/unhealthy eating and mind/body healthy eating on perceived dietary quality, respectively, are both significantly larger than the (non-significant) effect of healthy eating guideline on perceived dietary quality.

We then explored whether healthy/unhealthy eating and mind/body healthy eating, respectively, mediate the relationship between interest in healthy eating and perceived dietary quality (i.e., RQ3). We used bias-corrected bootstrapping to generate a 95\% confidence interval around each of the indirect effects, where mediation occurs if the confidence interval excludes zero. The results indicated that interest in healthy eating had a significant indirect effect on perceived dietary quality through mind/body healthy eating (95\% confidence interval $[\mathrm{CI}]=[0.05,0.29])$, whereas the indirect effect through healthy/unhealthy eating was not significant (95\% confidence interval $[\mathrm{CI}]=[-0.02,0.34])$.

Control variables: Of the control variables gender was negatively related to healthy/unhealthy eating $(\beta=-0.13, p<0.01)$, mind/body healthy eating $(\beta=-0.07, p=0.03)$, and healthy eating guideline $(\beta=-0.11, p<0.01)$, respectively, and positively related to perceived dietary quality $(\beta=0.14, p<0.01)$. This suggests that women are less likely than men to develop definitions of healthy eating and more likely than men to report healthy eating. Age was positively related to perceived dietary quality $(\beta=0.23, p<0.01)$ and education was negatively related to healthy/unhealthy eating $(\beta=-0.10, p=0.02)$ and healthy eating guideline $(\beta=-0.08, p=0.03)$. Income 
was positively related to healthy eating guideline $(\beta=0.13, p<0.01)$, whereas perceived dietary competency was negatively related to healthy/unhealthy eating $(\beta=-0.49, p<0.01), \mathrm{mind} /$ body healthy eating $(\beta=-0.29, p<0.01)$, and healthy eating guideline $(\beta=-0.22, p=0.03)$ and positively related to perceived dietary behavior $(\beta=0.89, p<0.01)$. 


\section{Table 4}

Estimated standardized coefficients.

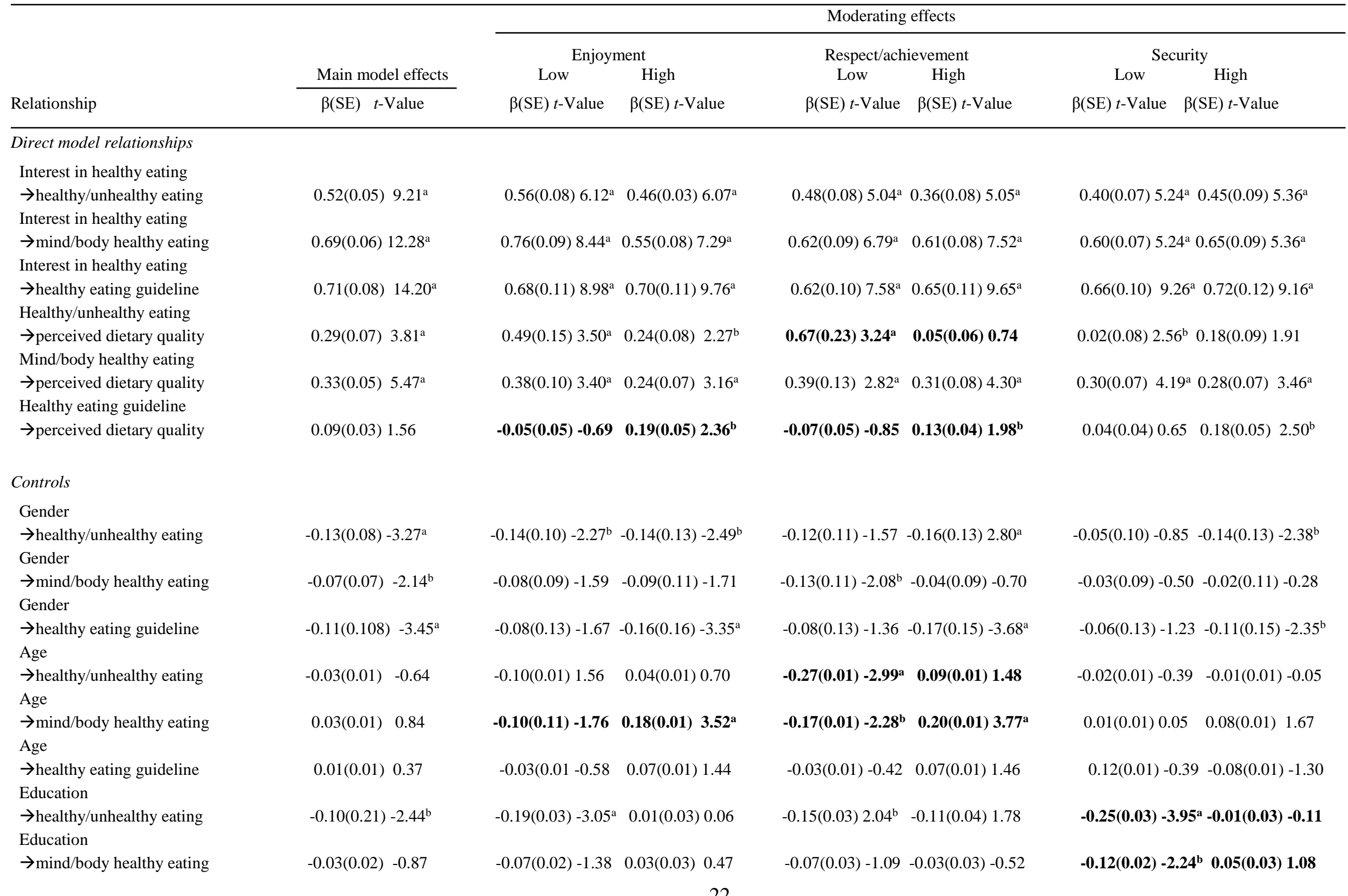




\begin{abstract}
$-0.08(0.02)-2.20^{\mathrm{b}}$

\subsection{5(0.02) 1.15}

$-0.13(0.03) 2.46^{\mathrm{b}} \quad 0.04(0.04) 0.08$

$-0.08(0.03)-1.51-0.10(0.04)-1.90$

$0.05(0.02) 0.84 \quad 0.03(0.03) 0.46$

$0.02(0.02) \quad 0.47$

$0.08(0.02) 1.51-0.04(0.03)-0.85$

0.04(0.05) $0.51 \quad 0.07(0.03) 1.14$

$0.05(0.03) 0.70 \quad 0.05(0.02) \quad 0.95$

$0.13(0.02) 3.94^{\mathrm{a}}$

$0.16(0.03) 2.92^{\mathrm{a}} \quad 0.09(0.03) 2.00^{\mathrm{b}}$

$0.17(0.03) 3.00^{\mathrm{a}} \quad 0.10(0.03) 2.15^{\mathrm{b}}$

$-0.49(0.05)-7.96^{\mathrm{a}}$

$-0.50(0.10)-4.96^{\mathrm{a}}-0.54(0.09) 5.88^{\mathrm{a}}$

$-0.73(0.14)-5.16^{\mathrm{a}}-0.36(0.07)-4.37^{\mathrm{a}}$

$-0.29(0.04)-6.55^{\mathrm{a}}$

$-0.22(0.06)-5.46^{\mathrm{a}}$

$0.14(0.08) 3.15^{\mathrm{a}}$

$0.23(0.01) \quad 5.00^{\mathrm{a}}$

$-0.02(0.02) \quad 0.47$

$0.03(0.02) \quad 0.70$

$0.89(0.09) \quad 9.28^{\mathrm{a}}$ $-0.41(0.08)-5.46^{\mathrm{a}}-0.25(0.06)-3.64^{\mathrm{a}}$

$-0.19(0.10)-2.76^{\mathrm{a}}-0.29(0.08)-4.88^{\mathrm{a}}$

$0.15(0.13) 1.90 \quad 0.20(0.13) 2.82^{\mathrm{a}}$

$0.37(0.04) 4.42^{\mathrm{a}} \quad 0.15(0.03) 2.40^{\mathrm{b}}$

$0.13(0.03) 1.70-0.16(0.03)-2.23^{b}$

$\begin{array}{llll}0.01(0.03) & 0.07 & 0.07(0.03) & 1.03\end{array}$

$0.94(0.17) 6.05^{\mathrm{a}} \quad 0.85(0.12) 6.25^{\mathrm{a}}$

\section{$-0.57(0.13)-5.31^{\mathrm{a}} \quad-0.12(0.04)-1.95$}

$-0.24(0.13)-2.93^{\mathrm{a}}-0.16(0.07)-2.85^{\mathrm{a}}$

$0.21(0.15) 2.29^{\mathrm{b}} \quad 0.23(0.17) 2.47^{\mathrm{b}}$

$0.48(0.04) 4.54^{\mathrm{a}} \quad 0.03(0.01) 0.34$

$0.15(0.04) 1.72-0.34(0.05)-3.25^{\mathrm{a}}$

$-0.01(0.03)-0.14^{\mathrm{a}} \quad 0.11(0.03) 1.32$

$0.90(0.21) 5.90^{\mathrm{a}} \quad 0.89(0.20) 5.38^{\mathrm{a}}$ $-0.13(0.03)-2.65^{\mathrm{a}}-0.03(0.04)-0.56$ $0.02(0.02) 0.40 \quad 0.04(0.030) \quad 0.59$ $0.02(0.02) 0.35 \quad 0.01(0.02) 0.06$ $0.15(0.03) 2.89^{\mathrm{a}} 0.13(0.03) 2.50^{\mathrm{b}}$ $-0.36(0.06)-4.46^{\mathrm{a}}-0.46(0.04)-4.85^{\mathrm{a}}$ $-0.18(0.05)-2.87^{\mathrm{a}}-0.27(0.06)-4.00^{\mathrm{a}}$ $-0.21(0.07)-3.67^{a}-0.21(0.08)-3.27^{a}$ $0.05(0.09) 0.89 \quad 0.16(0.13) 2.63^{\mathrm{a}}$ $0.22(0.03)-3.93^{\mathrm{a}} 0.22(0.03)-3.35^{\mathrm{a}}$ $0.12(0.02) 2.22^{\mathrm{b}}-\mathbf{- 0 . 1 3 ( 0 . 0 3 )}-2.02^{\mathrm{b}}$ $0.02(0.02) 0.34 \quad 0.06(0.03) 0.91$ $0.92(0.07) 7.59^{\mathrm{a}} 0.87(0.11) 6.19^{\mathrm{a}}$

Notes

Model fit (direct model effects): $\chi^{2}=828.00$ (d.f.=193, $p<0.01$ ); CFI=0.91; NFI=0.89; RMSEA=0.068; Hoelter(0.05)=197.

aSignificant on the $1 \%$ level; bsignificant on the $5 \%$ level. Sample $n=718$.

$\mathrm{R}^{2}$ (healthy/unhealthy eating) $=0.55 ; \mathrm{R}^{2}\left(\right.$ mind/body healthy eating) $=0.59 ; \mathrm{R}^{2}$ (healthy eating guideline) $=0.58 ; \mathrm{R}^{2}$ (perceived dietary quality) $=0.77$.

Coefficients in bold are statistically different $(p \leq 0.05)$; only differences in which at least one coefficient was significant were inspected.

Median splits created the low vs. high levels of the three personal values (i.e., enjoyment, respect/achievement, and security, respectively). 


\subsection{Results pertaining to $R Q$ 's 4 and 5}

The moderating effects pertaining to the three consumer definitions of healthy eating were investigated using multiple-group latent variable structural equation modeling (SEM) analysis with chi-square difference tests (Table 4).

Enjoyment: The influence of healthy eating guideline on perceived dietary quality was significantly higher for consumers with a high level of enjoyment $(\beta=0.19, p=0.02)$ than for consumers with a low level of enjoyment $(\beta=-0.05, p=0.49)$. A chi-square difference test suggested that the difference between coefficients was significant $\left(\Delta \chi^{2}=4.02, \Delta\right.$ d.f. $\left.=1, p=0.04\right)$. To test the potential moderated mediating (indirect) effect (i.e., healthy eating guideline on perceived dietary quality through interest in healthy eating), we used bias-corrected bootstrapping to generate a 95\% confidence interval around each of the indirect effects, where mediation occurs if the confidence interval excludes zero. When enjoyment is on a high level, the results indicated that interest in healthy eating had a significant positive indirect effect on perceived dietary quality through healthy eating guideline $(95 \%$ confidence interval $[\mathrm{CI}]=[0.02,0.24])$, whereas the indirect effect was nonsignificant when enjoyment is on a low level $(95 \%$ confidence interval $[\mathrm{CI}]=[-0.18,0.08])$. Hence, our results suggest that the mediating effect of interest in healthy eating on perceived dietary quality through healthy eating guideline is positively moderated by enjoyment.

Respect/achievement: Healthy/unhealthy eating had a positive influence on perceived dietary quality when the level of respect/achievement is low $(\beta=0.67, p<0.01)$ vs. high $(\beta=0.05, p=0.46)$ $\left(\Delta \chi^{2}=8.42, \Delta\right.$ d.f. $\left.=1, p<0.01\right)$. Also, healthy eating guideline had a positive effect on perceived dietary quality when respect/achievement is high $(\beta=0.13, p=0.05)$ vs. low $(\beta=-0.07, p=0.40)$ $\left(\Delta \chi^{2}=4.01, \Delta\right.$ d.f. $\left.=1, p=0.04\right)$. When respect/achievement is on a low level, the results indicated that interest in healthy eating had a positive significant indirect effect on perceived dietary quality through healthy/unhealthy eating $(95 \%$ confidence interval $[\mathrm{CI}]=[0.05,0.66])$, whereas the indirect effect was non-significant when respect/achievement is on a high level (95\% confidence interval 
$[\mathrm{CI}]=[-0.07,0.10])$. Hence, our results suggest that the mediating effect of interest in healthy eating on perceived dietary quality through health/unhealthy eating is negatively moderated by respect/achievement. The potential moderated mediating effect of interest in healthy eating on perceived dietary quality through healthy eating guideline was non-significant.

Security: No moderation effects were obtained for the relationships depicted in the conceptual model. However, the results suggested that several of the relationships involving the control variables were moderated by levels (low vs. high) of security, see below.

Control variables: Age was positively related to mind/body healthy eating when enjoyment is on a high level $(\beta=0.18, p<0.01)$ and negatively related to healthy/unhealthy eating when respect/achievement is on a low level $(\beta=-0.27, p<0.01)$. Also, age was positively related to $\operatorname{mind} /$ body healthy eating when respect/achievement is on a high level $(\beta=0.20, p<0.01)$ and negatively related to mind/body healthy eating when respect/achievement is on a low level $(\beta=-$ $0.17, p=0.02$ ). Education was negatively related to mind/body healthy eating when security is on a low level $(\beta=-0.12, p=0.03)$ and more negatively related to healthy/unhealthy eating with lower levels of security $(\beta=-0.25, p<0.01)$. Perceived dietary competency was more negatively related to $\operatorname{mind} /$ body healthy eating with lower levels of respect/achievement $(\beta=-0.57, p<0.01)$. Education was negatively related to perceived dietary quality with high levels of enjoyment $(\beta=-0.16, p=0.03)$ and security $(\beta=-0.13, p=0.04)$, respectively.

\subsection{Competing models}

To explore the robustness of the proposed conceptual model (Figure 1) three competing models were specified. In competing model 1 , interest in healthy eating was allowed also to have a direct effect on perceived dietary quality. The competing model was a reasonable fit to the data $\left(\chi^{2}=825.49\right.$, d.f. $=192, p<0.01 ; \mathrm{CFI}=0.91 ; \mathrm{NFI}=0.92 ; \mathrm{RMSEA}=0.068 ;$ Hoelter$\left.(0.05)=196\right)$ but was 
not an improvement over the proposed conceptual model $\left(\Delta \chi^{2}=2.51, \Delta\right.$ d.f. $\left.=1, p=0.11\right)$, although interest in healthy eating was positively related to perceived dietary quality $(\beta=0.67, p<0.01)$.

The conceptual model specifies healthy/unhealthy eating, mind/body healthy eating, and healthy eating guideline, respectively, as mediating variables between interest in healthy eating and perceived dietary quality. While this specification is consistent with past research indicating that interest in a specific area may lead a person to establish meanings/definitions related to that area (Tarkiainen and Sundqvist, 2009), other results indicate that such definitions may influence interest (e.g., Fischer and Arnold, 1994). Hence, in competing model 2, interest in healthy eating replaced the three definitions of healthy eating as an endogenous construct in the model, whereas the three definitions were specified as exogenous constructs influencing interest in healthy eating. Although healthy/unhealthy eating $(\beta=-0.08, p=0.02)$, mind/body healthy eating $(\beta=0.25, p<0.01)$, and healthy eating guideline $(\beta=0.29, p<0.01)$ were all significantly related to interest in healthy eating, the overall model fit statistics $\left(\chi^{2}=1312.58\right.$, d.f. $=210, p<0.01 ; \mathrm{CFI}=0.85 ; \mathrm{NFI}=0.82 ; \mathrm{RMSEA}=0.086$; Hoelter(0.05)=134) suggest that competing model 2 was not an improvement to the proposed conceptual model.

Competing model 3 was identical to the proposed conceptual model but without the control variables. This competing model was a relatively poor fit to the data $\left(\chi^{2}=952.92\right.$, d.f. $=113, p<0.01$; $\mathrm{CFI}=0.86 ; \mathrm{NFI}=0.84 ; \mathrm{RMSEA}=0.102 ; \operatorname{Hoelter}(0.05)=105)$. This result emphasizes that the proposed control variables should indeed be taken into account when seeking a more nuanced understanding of how consumers' definitions of healthy eating may transmit into dietary behavior. To conclude, we did not find compelling evidence suggesting that any of the three competing models were superior to the proposed conceptual model. 


\section{Discussion}

\subsection{Results and food policy implications}

Effects and implications of definitions of healthy eating: Definitions of healthy eating are a multifaceted concept. Depending on their construction, the results suggest that they will affect consumers' perceived dietary quality differently. Perhaps surprisingly, we found that healthy eating guideline was not significantly related to perceived dietary quality, whereas healthy/unhealthy eating and mind/body healthy eating both showed positive effects on perceived dietary quality. We suggest that one possible explanation for this result may be found in the trust literature, which indicates that people may trust their own definitions for healthy eating over a government program. Since food healthiness corresponds to a 'credence attribute' (Darby and Karni, 1973; Lassoued and Hobbs, 2015), the level of consumer trust in different sources of information (i.e., including their constructed definitions of healthy eating) is likely to be important for consumers' subsequent perception of their dietary quality (Grebitus et al., 2015). In that respect, public health campaigns have generally been conducted from the assumption that consumers are capable of understanding and willing to act upon official food guidelines (Kristensen et al., 2013). This approach is consistent with evidence from the trust literature suggesting that consumers have more trust in information from authorities that promote individuals' wellbeing and healthiness, such as government institutions, as compared with commercial companies (Montserrat et al., 2008). However, it is also known that personal components (e.g., when consumers develop more 'personal' definitions of healthy eating) may be associated with even a higher level of trust because of self-reliance (e.g., Hall et al., 2002; Hansen and Thomsen, 2013).

The findings that healthy eating guideline was not significantly related to perceived dietary quality, whereas healthy/unhealthy eating and mind/body healthy eating both showed positive effects on perceived dietary quality have important implications for food health authorities and policy makers. Healthy eating campaigns focusing especially on optimizing nutritional value may 
not effectively promote healthy food behavior unless they are complemented with other views on healthy food consumption. For instance, they may support the view that eating unhealthy can - to a certain degree - be seen as acceptable, since it can be compensated for by consuming healthy food as well. There are several nutritional guidelines that might be associated with such definitions of healthy eating; for instance, the British Food Standards Agency's 'Eat-Well-Plate' (Food Standards Agency, 2018). The Eat-Well-Plate illustrates a recommended healthy balance between the amounts of foods from different food categories; including a category for 'Food and Drinks High in Fat and/or Sugar' in which, among others, sweets, soft drinks, and chocolate are displayed. However, food authorities may wish to further investigate how to develop food health campaigns and recommendations that consumers may associate with a healthy/unhealthy eating definition.

Food authorities may also consider focusing on campaigns that stress the importance of being present and paying 'mindful' attention to the body when eating and drinking. Indeed, research suggests that mindful food consumption leads consumers to be more aware of physiological cues, which in turn is related to positive weight outcomes (Van de Veer et al., 2015).

Effects and implications of interest in healthy eating: As expected from the conceptual framework, interest in healthy eating was positively related to healthy/unhealthy eating, mind/body healthy eating, and healthy eating guideline, respectively, although the influences on $\mathrm{mind} / \mathrm{body}$ healthy eating and healthy eating guideline were both significantly larger than the effect of interest in healthy eating on healthy/unhealthy eating. We also found that interest in healthy eating had a significant indirect effect on perceived dietary quality through mind/body healthy eating. These results are of pivotal importance to food health policy makers and authorities. Food health campaigns may aim at improving consumers' interest in healthy eating in order to positively influence both their definitions of healthy eating (with special attention to promoting healthiness as a balance between mind and body) and perceived dietary quality. Food policy makers and authorities may seek various ways in accomplishing this; including informational and educational 
activities, labeling, among others (Van Loo et al., 2017), although influencing levels of interest is not easily accomplished and may require an ambitious and long-term effort (e.g., Arnocky et al., 2007; Aertsens et al., 2009).

Effects and implications of personal values: Consistent with the proposed conceptual model, the results were modified in several ways when consumers' personal values were taken into account.

First, a number of moderating effects were detected. (a) Healthy eating guideline had a positive influence on perceived dietary quality with a high level of enjoyment. (b) When respect/achievement was on a low level, healthy/unhealthy eating had a larger positive effect on perceived dietary quality. (c) When respect/achievement was on a high level, healthy eating guideline had a positive effect on perceived dietary quality. (d) No moderation effects on model relationships were obtained for security.

Second, the results also indicated that personal values may significantly moderate the potential mediating effect of healthy eating definitions in the relationship between interest in healthy eating and perceived dietary quality. We found that the mediating effect of interest in healthy eating on perceived dietary quality through healthy eating guideline was positively moderated by enjoyment. We also found that the mediating effect of interest in healthy eating on perceived dietary quality through healthy/unhealthy eating was negatively moderated by respect/achievement. The results suggest that food authorities have the opportunity of including personal values when addressing consumers in order to improve their dietary quality. For example, they may seek to promote that following official guidelines for healthy eating is an enjoyable experience that will make consumers feel good about their healthiness and/or will contribute to increased feelings of (self-)respect and achievement. In contrast, the results indicate that food authorities should pay less attention to the personal value security when seeking to improve consumer dietary quality. 
Effects and implications of control variables: Several of the control variables had significant effects. Interestingly, we found that women are less likely than men to develop definitions of healthy eating and more likely than men to report higher levels of perceived dietary quality. While the latter effect is consistent with previous research (e.g., Ureña et al., 2008), the result underlines that healthy dietary behavior is not just gender-stereotypic but may also be influenced by consumer psychographics. Indeed, one explanation for women's lower propensity to develop definitions of healthy eating may be found in the findings that perceived dietary competency was negatively related to all three definitions of healthy eating. This is because research has shown that women generally show a higher level of dietary competency than men (Beardsworth et al., 2002) and also suggests that increased competency makes individuals more likely to process detailed and contextspecific information and less likely to rely on abstractions (e.g., heuristics, meanings/definitions) when carrying out their behavior (Bettman et al., 1998). Moreover, the results are also consistent with the finding that education was negatively related to both healthy/unhealthy eating and healthy eating guideline as education has been found to positively correlate with perceived dietary competency (Dickson-Spillman and Siergrist, 2010; Lin and Yen, 2010). Similar to previous research, we also found that age was positive related to perceived dietary quality (Ares and Gámbaro, 2007).

\subsection{Limitations and future research}

This study concentrated on analyzing the consumer population of one society/culture. Although obesity is present in many societies, this could mean that the results may suffer from a lack of generalizability when other countries are considered. For example, it is known that cultural factors, such as familial roles, ways of life, practices, among others, may directly or indirectly be related to healthy eating and may also influence the adoption of healthy eating definitions (Kreuter et al., 2002). Consistent with previous research, we found that perceived dietary quality was negatively 
related to BMI and positively related to perceived dietary competency and that women were more likely than men to report a healthy dietary behavior. However, perceived dietary quality is a selfreported variable, which may deviate from actual dietary behaviors. Hence, future research may wish to use choice experiments, scanner data, and/or include measures on self-reported actual behaviors such as intake of fruit, vegetables, sweets and snacks.

While comprehensive models of healthy eating behavior may include genetic, biological, behavioral, psychological, and environmental variables (French et al., 2012), the focus of the present study is on the psychological and behavioral level. This means that additional consumer factors (e.g., perceived body health, social norms and values, food traditions, among others) may further detail the results. Also, we did not consider whether consumers' trust in food authorities, food suppliers, and other market agents may further add to our understanding of the interplay between interest in healthy eating, definitions of healthy eating, and perceived dietary quality. Future research may wish to take such additional factors into account. 


\section{Appendix A}

BMI categories.

Percentages of the sample compared to the Danish population ${ }^{\mathrm{a}}$

\begin{tabular}{|c|c|c|c|c|}
\hline & \multicolumn{4}{|c|}{ BMI category } \\
\hline & $<18.5$ & $18.5-<25.0$ & $\geq 25.0-<30.0$ & $\geq 30.0$ \\
\hline All respondents & $1.4(2.4)$ & $47.1(46.6 \%)$ & $39.8(34.2)$ & $11.7(16.8)$ \\
\hline \multicolumn{5}{|l|}{ Gender } \\
\hline Male & $0.6(1.3)$ & $44.2(41.0)$ & $42.6(40.6)$ & $12.6(17.1)$ \\
\hline Female & $2.0(3.5)$ & $49.3(52.0)$ & $37.7(27.8)$ & $11.0(16.6)$ \\
\hline \multicolumn{5}{|l|}{ Age (male) } \\
\hline $18-24^{\mathrm{b}}$ & $0.0(5.8)$ & $72.7(66.5)$ & $27.3(21.1)$ & $0.0(6.6)$ \\
\hline $25-34$ & $0.0(1.0)$ & $62.5(50.7)$ & $29.2(35.0)$ & $8.4(13.3)$ \\
\hline $35-44$ & $0.0(0.5)$ & $43.6(39.1)$ & $43.6(42.4)$ & $12.7(18.1)$ \\
\hline $45-54$ & $0.0(0.3)$ & $43.1(33.0)$ & $41.2(46.4)$ & $15.7(20.4)$ \\
\hline $55-64$ & $1.3(0.5)$ & $34.2(30.0)$ & $53.2(47.6)$ & $11.4(21.9)$ \\
\hline $65-74$ & $1.5(0.4)$ & $43.9(31.0)$ & $43.9(46.6)$ & $10.6(22.0)$ \\
\hline $75-88^{c}$ & $0.0(0.9)$ & $50.0(39.8)$ & $37.5(44.4)$ & $12.5(15.0)$ \\
\hline \multicolumn{5}{|l|}{ Age (female) } \\
\hline $18-24^{\mathrm{b}}$ & $11.1(8.5)$ & $66.7(67.5)$ & $13.9(15.9)$ & $8.3(8.1)$ \\
\hline $25-34$ & $0.0(4.1)$ & $59.6(58.5)$ & $25.5(22.5)$ & $14.9(15.0)$ \\
\hline $35-44$ & $1.4(2.3)$ & $51.4(52.6)$ & $33.3(27.0)$ & $13.9(18.1)$ \\
\hline $45-54$ & $1.3(1.8)$ & 44.7 (46.7) & $38.2(30.0)$ & $15.8(21.5)$ \\
\hline $55-64$ & $0.0(2.3)$ & $44.9(45.5)$ & $50.0(32.7)$ & $5.0(19.5)$ \\
\hline $65-74$ & $0.0(2.8)$ & $46.8(45.7)$ & $45.6(33.5)$ & $6.3(17.9)$ \\
\hline $75-88^{c}$ & $0.0(4.0)$ & $30.0(49.6)$ & $45.0(32.8)$ & $25.0(13.6)$ \\
\hline
\end{tabular}

\section{Notes}

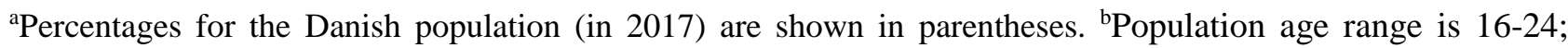
'population age range is ' 75 , or older'.

Source (population percentages): The Danish Health Authority, 2017.

BMI categories (WHO, 2017): <18.5: underweight; 18.5- $\leq 25.0$ : normal range; >25.0: overweight; $\geq 30.0$ : obese. Sample, $n=718$. 


\section{Appendix B}

Items used to measure the constructs used in the study

Percentages in scale categories

1 or 23,4 or $5 \quad 6$ or 7

Healthy/unhealthy eating ${ }^{\mathrm{a}}$

Food related health means:

X1 a good balance between healthy and unhealthy food

$\mathrm{X} 2$ that I eat both healthy and unhealthy food

$13.2 \quad 55.6 \quad 31.1$

$\mathrm{X} 3$ that an unhealthy diet is supplemented with healthy food

$18.5 \quad 55.9 \quad 25.6$

Mind/body healthy eating ${ }^{\text {a }}$

Food related health means:

$\mathrm{X} 4$ feeling good about what I eat

X5 that my body and soul are in balance

$22.1 \quad 55.4 \quad 22.4$

X6 that both my body and soul are well

$\mathrm{X} 7$ that my diet takes both my body and soul into account

$\begin{array}{lll}5.8 & 52.8 & 41.4\end{array}$

$\begin{array}{lll}3.2 & 39.0 & 47.8\end{array}$

Healthy eating guideline $e^{\mathrm{a}}$

Food related health means:

$\mathrm{X} 8$ following the official dietary guidelines

X9 eating ' 6 -a-day'

$5.3 \quad 51.5 \quad 43.1$

$\mathrm{X} 10$ consuming food in accordance with the food pyramid

$\mathrm{X} 11$ that my food consumption is in accordance with the

$\begin{array}{lll}11.8 & 53.6 & 34.5\end{array}$

$\begin{array}{lll}15.5 & 60.2 \quad 25.4\end{array}$

National Board of Health's recommendations

$13.8 \quad 60.0 \quad 26.2$

Interest in healthy eating ${ }^{\mathrm{a}}$

X12 I'm usually bored when I listen to discussions about food and health* $\quad 48.0 \quad 41.1 \quad 11.0$

X13 Eating healthy is not important to me*

$\begin{array}{lll}61.0 & 34.5 & 4.6\end{array}$

X14 In general, I'm very interested in healthy food products

$10.0 \quad 49.1 \quad 41.0$

Perceived dietary quality ${ }^{\mathrm{a}}$

$\mathrm{X} 15$ On average, I believe that my food intake is healthy

$\mathrm{X} 16$ On average, I believe that my intake of drinks is healthy

$\begin{array}{lll}9.2 & 50.2 \quad 40.7\end{array}$

$\mathrm{X} 17$ All in all, I don't believe that I have a healthy diet*

Enjoyment ${ }^{\mathrm{b}}$

X18 Excitement

X19 Fun \& enjoyment

Respect/achievement ${ }^{\mathrm{b}}$

X20 Sense of accomplishment

$1.0 \quad 34.9$

64.3

X21 Self-respect

X22 Self-fulfillment

X23 Being well-respected

$\begin{array}{lll}2.2 & 35.4 & 62.2\end{array}$

Security $^{\mathrm{b}}$

X24 Sense of belonging

X25 Warm relationships

Perceived dietary competency ${ }^{\mathrm{a}}$

X27 As far as shopping for healthy food is concerned, I consider myself highly competent 11.7

I can easily distinguish between healthy and unhealthy food products\#

* Item reverse coded. These items were recoded before entering the subsequent analyses so that all items were in the same direction. \#Item deleted due to low $(<0.50)$ item-total correlation.

${ }^{a}$ The applied item measurement scales all ranged from 1(=strongly disagree) to 7(=strongly agree).

${ }^{\mathrm{b}}$ The applied item measurement scales all ranged from 1(=not at all important) to 7(=extremely important) 


\section{References}

Aertsens, J., Verbeke, W., Mondelaers, K., Van Huylenbroeck, G., 2009. Personal determinants of organic food consumption: a review. Brit. Food J. 111, 1140-1167.

Ajzen, I., Fishbein, M., 1973. Attitudinal and normative variables as predictors of specific behavior. J. Pers. Soc. Psychol. 27, 41-57.

Ares, G., Gámbaro, A., 2007. Influence of gender, age and motives underlying food choice on perceived healthiness and willingness to try functional foods, Appetite 49, 148-158.

Arnocky, S., Stroink, M., DeCicco, T., 2007. Self-construal predicts environmental concern, cooperation, and conservation. J. Environ. Psychol. 27, 255-264.

Bagozzi, R.P. Yi, Y., 1988. On the Evaluation of Structural Equation Models. J. Acad. Market Sci. $16,74-94$.

Bartali, B., Salvini, S., Turrini, A., Lauretani, F., Russo, C.R., Corsi, A.M., Bandinelli, S. D'Amicis, A., Palli, D., Guralnik, J.M., Ferrucci, L., 2003. Age and Disability Affect dietary Intake. J. Nutr. 133, 68-73.

Beatty, S.E., Talpade, S., 1994. Adolescent Influence in Family Decision Making: A replication With Extension. J. Consum. Res. 21, 332-341.

Beatty, S. E., Kahle, L. R., Homer, P., 1988. The Involvement-Commitment Model: Theory and Implications. J. Bus. Res. 16, 149-167.

Beardsworth, A., Brynan, A., Keil, T., Good, J., Haslam, C., Lancashire, E., 2002. Women, men and food: the significance of gender for nutritional attitudes and choices, Brit. Food J. 104, 470-491.

Berg, L., 2007, Competent consumers? Consumer competence profiles in Norway. International J. Consum. Stu. 31, 418-427.

Bettman, J.R., Luce, M.F., Payne, J.W. 1998. Constructive consumer choice processes. J. Consumer 
Res., 25, 187-217.

Beydoun, M.A., Wang Y., 2008. How do socio-economic status, perceived economic barriers and nutritional benefits affect quality of dietary intake among US adults? Eur. J. Cli. Nutr. 62, 303313

Browne, M.W., Cudeck, R., 1993. Alternative ways of assessing model fit. In K.A. Bollen, Long, J.S. (Eds.), Testing Structural Equation Models (136-162). Beverly Hills, CA: Sage.

Buchmueller, T.C., Johar, M., 2015. Obesity and health expenditures: Evidence from Australia. Eco. Hum. Biol. 17, 42-58.

Buckley, M.R., Cote, J.A., Comstock, S.M., 1990. Measurement errors in behavioral sciences: The case of personality/attitude research. Educ. Psychol. Meas. 50, 447-474.

Caroll, K.A., Samek, A.S., Zepeda, L., 2016. Product Bundling as a Behavioral Nudge: Investigating Consumer Fruit and Vegetable Selection using Dual-Self Theory. Paper presented at the Agricultural \& Applied Economics Association Annual Meeting, Boston, Massachusetts, July 31-August 2.

Casotti, L., 2004. Conflicts Between Pleasure, Aesthetics and Health in Food Consumption: An Exploratory Study in Brazil. J. Marketing Man. 20, 545-557.

Chandon, P., Wansink, B., 2007. The Biasing Health Halos of Fast-Food Restaurant Health Claims: Lower Calorie Estimates and Higher Side-dish Consumption Intentions. J. Consum Res. 34, 301-314.

Coveney, J., 2004. A qualitative study exploring socio-economic differences in parental lay knowledge of food and health: implications for public health nutrition. Pub. Health Nutr. 8, 290297.

Cumming, G., 2009. Inference by eye: reading the overlap of independent confidence intervals. Stat. Medic. 28, 205-220.

Darby, M. R., Karni, E., 1973. Free competition and the optimal amount of fraud. J. Law Econ. 
$16,67-86$.

Davenport, L.A., Radcliffe, J., Chen, T-A., Cullen, K.W., 2014. Adolescents who perceive their diet as healthy consume more fruits, vegetables and milk and fewer sweet drinks. Int. J. Child Health and Nutr. 3, 124-129.

de Maya, S.R., López-López, I., Munuera, J.L., 2011. Organic food consumption in Europe: International segmentation based on value system differences. Ecol. Econ. 70, 1767-1775. de Pelsmacker, P., Moons, I., Bavarossa C., 2016. A self-identity driven model of electric car adoption and the moderating role of personal values, Paper presented at the15th International Conference Marketing Trends 2016 Venice. ed. /Jean-Claude Andreani;

Umberto Collesei. Paris-Venice: Marketing Trends Association.

Delormier, T., Frohlich, K.L., Potvin, L., 2009. Food and eating as social practice - understanding eating patterns as social phenomena and implications for public health. Sociol. Health. Illn. $31,215-228$.

Dibley, A., Baker, S., 2001. Uncovering the Links between Brand Choice and Personal Value among Young British and Spanish Girls. J. Consum. Beh. 1, 77-94.

Dickson-Spillman M., Siergrist M., 2010. Consumers' knowledge of healthy diets and its Correlation with dietary behaviour. J. Hum Nutr. Diet 24, 52-60.

DST (Danmarks Statistik) (2018), Statbank Denmark: http://www.dst.dk/da/Statistik/statistikbanken\# (accessed 18 January 2018).

Ecks, S., 2009. Welcome Home, Descartes! Rethinking the Anthropology of the Body. Perspect. Biol. Med. 52, 153-158.

Eek, F., Östergren, P.O., 2007. Factors Associated with BMI Change over Five Years in a Swedish Adult Population. Results from the Scania Public Health Cohort Study. Scan J. Public Health $37,532-544$.

Eurostat (2018), Overweight and obesity - BMI statistics: http://ec.europa.eu/eurostat/statistics 
explained/index.php/Overweight_and_obesity___BMI_statistics (accessed 14 July 2018).

Finch, J.E., 2005. The Impact of Personal Consumption Values and Believes on Organic Food Purchase Behaviour. J. Food Prod. Mark. 11, 63-76.

Fisher, R.J., 1993. Social desirability bias and the validity of indirect questioning. J. Cons. Res. 20, 303-315.

Fischler C., 1990. L’homnivore. Odile Jacob: Paris.

Fisher, E., Arnold, S.J., 1994. Sex, gender identity, gender role attitude, and consumer behavior. Psychol. Mark. 11, 163-182.

Fitzgerald, N., Damio, G., Segura-Pérez, S., Pérez-Escamilla, R., 2008. Nutrition knowledge, food label use, and food intake patterns among latinas with and without type 2 diabetes. J. Am. Diet Assoc. 108, 960-967,

Food Standards Agency, 2018, January 10: Enjoy healthy eating. Retrieved from https://www.enjoyhealthyeating.info/nutrition/adolescents/healthy-eating

Fornell, C., Larcker, D.F., 1981. Evaluating Structural Equation Models with Unobservable Variables and Measurement Error. J. Mark. Res. 18, 39-50.

Forstmann, M., Burgmer P., Mussweiler, T., 2012. The mind is willing, but the flesh is weak: The effects of mind-body dualism on health behavior. Psychol. Sci. 23, 1239-1245.

Frambach, R.T., Prabhu, J., Verhallen, T.M.M., 2003. The influence of business strategy on new product activity: The role of market orientation. Int. J. Res. Mark. 20, 377-397.

Franke, N., Keinz, P., Steger, C., 2009. Testing the Value of Customization: When Do Customers Really Prefer Products Tailored to Their Preferences? J. Mark. 73, 103-121.

French, S.A., Story, M., Hannan, P., Breitlow, K.K., Jeffery, R.W., Baxter, J.S., Snyder, M.P., 1999. Cognitive and Demographic Correlates of Low-Fat Vending Snack Choices among Adolescents and Adults. J. Am. Diet Assoc.99, 471-74. 
French, S.A., Epstein, L.H., Jeffery, R.W., Blundell, J.E., Wardle, J., 2012. Eating Behavior Dimensions: Associations With Energy Intake And Body Weight: A Review. Appetite 59, 541549.

Geeroms, N., Verbeke, W., Van Kenhove, P., 2008a. Health advertising to promote fruit and vegetable intake: application of health-related motive segmentation. Food Qual. Prefer. 19, 481497.

Geeroms, N., Verbeke, W., Van Kenhove, P., 2008b. Consumers' health-related motive orientations and ready meal consumption behavior. Appetite, 51, 704-712.

Grebitus, C., Steiner, B., Veeman, M., 2015. The roles of human values and generalized trust on stated preferences when food is labeled with environmental footprints: Insights from Germany. Food Policy 52, 84-91.

Greene, W.H., 2000. Econometric analysis. Upper Saddle River, NJ: Prentice Hall.

Hair, J.F., Black, W.C., Babin, B.J., Anderson, R.E., 2014. Multivariate Data Analysis, Pearson Prentice Hall, 7th edition.

Halkier, B., 2016. Consumption Challenged, Taylor \& Francis: New York.

Hall,M. A., Camacho, F., Dugan, E., Balkrishnan, R., 2002. Trust in the medical profession:

Conceptual and measurement issues. Health Serv. Res. 37, 1419-1439.

Hansen, T., Thomsen, T.U., 2013. I know what I know, but I will probably fail anyway: How learned helplessness moderates the knowledge calibration-dietary choice quality relationship. Psychol. Mark. 30, 1008-1028.

Hansen, T., Sørensen, M.I., Eriksen, M.L.R., 2018. How the Interplay between Consumer Motivations and Values Influences Organic Food Identity and Behavior. Food Policy 74, 39-52.

Hilger, J., Loerbroks, A., Diehl K., 2017. Eating behaviour of university students in Germany:

Dietary intake, barriers to healthy eating and changes in eating behaviour since the time of matriculation. Appetite 109, 100-107. 
Hill, D.C., Moss, R.H., Sykes-Muskett, B., Conner, M., O’Connor, D.B., 2018. Stress and eating behaviors in children and adolescents: Systematic review and meta-analysis. Appetite $123,14-22$.

Hoelter, J.W., 1983. The analysis of covariance structures: goodness-of-fit indices. Sociol. Methods Res. 11, 325-344.

Homer, P.M., Kahle, L.R., 1988. A Structural Equation Test of the Value-Attitude-Behaviour Hierarchy. J. Pers. Soc. Psychol. 54, 638-646.

Howlett, E., Burton, S., Kozup, J., 2008. How Modification of the Nutrition Facts Panel Influences Consumers at Risk for Heart Disease: The Case of Trans Fat. Journal of Public Policy \& Marketing 27, 83-97.

Hughner, R.S., Maher, J.K., 2006. Factors that Influence Parental Food Purchases for Children: Implications for Dietary Health. J. Mark. Man. 22, 929-954.

Hui, S.K., Bradlow, E.T., Fader, P.S. 2009. Testing Behavioral Hypotheses Using an Integrated Model of Grocery Store Shopping Path and Purchase Behavior. J. Consum. Res. 36, 478-493. Jeong, J-Y., Ham, S., 2018. Application of the Health Belief Model to customers' use of menu labels in restaurants. Appetite 123, 208-215.

Johnston, C.S., 1995. The Rokeach value survey: Underlying structure and multidimensional scaling. J. Psychol. 129, 583-597.

Jones, E., Akbay, C., Roe, B., Chern, W.S. 2003. Analyses of Consumers' Dietary Behavior: An Application of the AIDS Model to Supermarket Scanner Data. Agribusiness, 19, 203-221.

Kahle, L.R., ed., 1983. Social Values and Social Change: Adaptation to Life in America, New York: Praeger.

Kahle, L.R., Kennedy, P., 1989. Using the list of values (LOV) to understand consumers. J. Consum. Mark. 6, 5-12.

Kahle, L., Liu, R., Watkins, H., 1992. Psychographic Variation Across United States 
Geographic Regions, in Advances in Consumer Research book, eds. John F. Sherry and Brian Sternthal, Provo, UT: Association for Consumer Research 18, 346-352.

Khare, A., Inman, J.J., 2006. Habitual Behavior in American Eating: The Role of Meal Occasions. J. Consum. Res. 32, 567-575.

Kidwell, B., Hardesty, D.M., Childers, T.L., 2008. Emotional Calibration Effects on Consumer Choice. J. Consum. Res. 35, 611-621.

Kreuter, M.W., Lukwago, S.N., Bucholtz, D.C., Clark, E.M., Sanders-Thompson, V., 2002. Achieving Cultural Appropriateness in Health Promotion Programs: Targeted and Tailored Approaches. Health Edu. Beh. 30, 133-146.

Kristensen, D.B., Askegaard, S., Jeppesen, L.H., 2013. If it makes you feel good it must be right': Embodiment strategies for healthy eating and risk management. J. Consum. Beh. 12, 243-252.

Kropp, F., Lavack, A.M., Holden, S.J.S., 1999. Smokers and Beer Drinkers: Values and Consumer Susceptibility to Interpersonal Influence. J. Consum. Mark. 16, 536-537.

Lassoued, R., Hobbs, J.E., 2015. Consumer confidence in credence attributes: The role of brand trust, Food Policy 52, 99-107.

Lin C.T., Yen, S.T., 2010. Knowledge of dietary fats among US consumers, J. Am. Diet Assoc. $110,613-618$.

Loo, E.J. Van, Hoefkens, C., Verbeke, W., 2017. Healthy, sustainable and plant-based eating: Perceived (mis)match and involvement-based consumer segments as targets for future policy. Food Policy 69, 46-57.

Luomala, H.T., Paasovaara, R., Lehtola, K., 2006. Exploring consumers' Health Meaning Categories: Towards a Health Consumption Meaning Model. J. Consum Beh. 5, 269-279. Luomala, H., Jokitalo, M., Karhu, H. Hietaranta-Luoma, H-L., Hopia, A., Hietamäki, S., 2015. Perceived health and taste ambivalence in food consumption. J. Consum. Mark. 32, 290-301. 
McCarty, J.A., Shruni, L.J. 1993. A Structural Equation Analysis of the Relationships of Personal Values, Attitudes and Beliefs About Recycling, and the Recycling of Solid Waste Products. Advances in Consumer Research 20, 641-646.

McCarthy, M., Cluzel, E., Dressel, K., Newton, R., 2013. Food and health research in Europe: Structures, gaps, and futures. Food Policy 39, 64-71.

McLaughlin, E.A., Smith, J.E., Serier, K.N., Smith, J.M., Santistevan, D., Simmons, J.D., 2018. What does self-reported "dieting” mean? Evidence from a daily diary study of behavior. Appetite 127, 79-86.

Metcalfe, J.J., Fiese, B.H., 2018. Family food involvement is related to healthier dietary intake in preschool-aged children. Appetite 126, 195-200.

Mokdad, A.H., Ford, E.S., Bowman, B.A., Dietz, W.H., Vinicor, F., Bales, V.S., Marks, J.S., 2003. Prevalence of Obesity, Diabetes, and Obesity Related Health Risk Factors. J. Am. Med. Assoc. 289, 76-79.

Monteiro, C.A., Conde, W.L., Popkin, B.M., 2001. Independent Effects of Income and Education on the Risk of Obesity in the Brazilian Adult Population. J. Nutr. 131, 881S-86S.

Montserrat, C-F., Gill, J.M., Traill, W.B., 2008. Consumer acceptance, valuation of and attitudes towards genetically modified food: Review and implications for food policy. Food Policy 33, 99-111.

Moorman, C., Matulich, E., 1993. A Model of Consumers' Preventive Health Behaviors: The Role of Health Motivation and Health Ability. J. Consum. Res. 20, 208-228.

Netemeyer, R.G., Boles, J.S., McKee, D.O., McMurrian, R.C., 1997. An investigation into the antecedents of organizational citizenship behaviors in a personal selling context. J. Mark. 61, 85-98.

Olsen, S.O., 2003. Understanding the Relationship between Age and Seafood Consumption: The Mediating Role of Attitude, Health Involvement and Convenience. Food Qual. Prefer. 14, 199- 
209.

Orquin, J.L., Scholderer, 2015. Consumer judgments of explicit and implied health claims on foods: Misguided but not misled. Food Policy 51, 144-157.

Osgood, C.E., Tannenbaum, P.H., 1955. The principle of congruity in the prediction of attitude change. Psychol. Rev. 62, 42-55.

Pollan M., 2008. In Defence of Food. Penguin: New York.

Reynolds .B, Ortengren A., Richards J.B., de Wit H., 2006. Dimensions of impulsive behavior: Personality And behavioral measures. Personal. Individ Differ. 40, 305-315.

Rizk, M.T., Treat, T.A., 2014. An Indirect Approach to the Measurement of Nutrient-Specific Perceptions of Food Healthiness. Ann. Behav. Med. 48, 17-25.

Rokeach, M., 1973. The Nature of Human Values. New York: Free Press.

Ronto, R., Ball, L., Pendergast, D., Harris, N., 2016. Adolescents' perspectives on food literacy and its impact on their dietary behaviours. Appetite, 107, 549-557.

Sapp, S.G. and Jensen, H.H., 1998. An Evaluation of the Health Belief Model for Predicting Perceived and Actual Dietary Quality. J. Appl. Soc. Psych. 28, 235-248.

Schwartz, S.H., 1994. Are there universal aspects in the structure and contents of human values? J. Soc. Issues 50, 19-45.

Schwartz, S.H., Sagiv L., 1995. Identifying culture-specifics in the content and structure of Values. J. Cross. Cult. Psychol. 26, 92-116.

Sharif, M.Z., Rizzo, S., Marino, E., Belin, T.R., Glik, D.C., Kuo, A.A., Ortega, A.N., Prelip, M.L., 2016. The association between self-rated eating habits and dietary behavior in two Latino neighborhoods: Findings from Proyecto MercadoFRESCO, Prev. Med. Rep. $3,270-275$.

Shukri, M., Jones, F., Conner, M., 2018. Relationship between work-family conflict and unhealthy eating: Does eating style matter? Appetite 123, 225-232. 
Slater, J.J. 2016. Self-Perceived Eating Habits and Food Skills of Canadians. J. Nutr. Educ. Behav., $48,486-495$.

Swan, E., Bouwman, L., Hiddink, G.J., Aarts, N., Koelen, M., 2015. Profiling healthy eaters. Determining factors that predict healthy eating practices among Dutch adults. Appetite 89, 122-130.

Swanson, M., Schoenberg, N.E., Davis, R., Wright, S., Dollarhide K., 2013. Perceptions of Healthy Eating and Influences on the Food Choices of Appalachian Youth. J. Nutr. Educ. Behav., 45, 147-153.

Tarkiainen, A., Sundqvist, S., 2009. Product Involvement in organic food consumption: Does ideology meet practice? Psychol. Mark. 26, 844-863.

Taubes, G., 2012. Cancer research. Unraveling the obesity-cancer connection. Science 335, 30-32.

The Danish Health Authority, 2017. Danskernes Sundhed - Den National Sundhedsprofil 2017 (in Danish), Sundhedsstyrelsen, 134 pages.

Thompson, C.J., Troester, M., 2002. Consumer Value Systems in the Age of Postmodern Fragmentation: The Case of the Natural Health Microculture. J. Consum. Res. 28, 550-571.

Todd, P.M., Gigerenzer, G., 2003. Bounded rationality to the world. J. Eco. Psychol. 24, 143-165.

Ureña, F., Bernabéu, R., Olmeda, M., 2008. Women, men and organic food: differences in their attitudes and willingness to pay. A Spanish case study. Int J Consum Stud. 32, 18-26.

Van de Veer, E., Van Herpen, E., Van Trijp, H.C.M., 2015. Body and Mind: Mindfulness Helps Consumers to Compensate for Prior Food Intake by Enhancing the Responsiveness to Physiological Cues. J. Consum. Res. 42, 783-803.

Van Loo, E.J.,, Hoefkens, C., Verbeke, W., 2017. Healthy, sustainable and plant-based eating: Perceived (mis)match and involvement-based consumer segments as targets for future policy. Food Policy 69, 46-57.

Velazquez, C.E., Pash, K.E., Ranjit, N., Mirchandani, G., Hoelscher, D.M., 2011. Are adolescents' 
perceptions of dietary practices associated with their dietary behaviors? J. Am. Diet Assoc. $111,1735-1740$.

Vincze, L., Rollo, M.E., Hutchesson, M.J., Burrows, T.L., MacDonald-Wicks, L., Blumfield, M., Collins, C.E., 2017. A cross sectional study investigating weight management motivations, methods and perceived healthy eating and physical activity influences in women up to five years following childbirth. Midwifery 49, 124-133.

Wang, Z., Patterson, C.M., Hills, A.P., 2002. Association between overweight or obesity and household income and parental body mass index in Australian youth: Analysis of the Australian National Nutrition Survey, 1995. Asia Pacific J Clin Nutr. 11, 200-205.

Warshaw, P.R., 1980. Predicting purchase and other behaviors from general and contextually specific intentions. J. Mark. Res. 17, 26-33.

WHO, 2017. Obesity and overweight. Fact sheet fs311, February 2018: http://www.who.int/mediacentre/factsheets/fs311/en/

Ye, J., Marinova, D., Singh, J., 2007. Strategic change implementation and performance loss in the front lines. J. Mark. 71, 156-171.

Zaichkowsky, J.L., 1985. Measuring the Involvement Construct. J. Consum. Res. 12, 341-352.

Zinkhan, G.M., Braunsberger, K., 2004. The complexity of consumers' cognitive structures and its relevance to consumer behaviour. J. Bus. Res. 57, 575-582. 